Elsevier Editorial System(tm) for Fusion Engineering and Design

Manuscript Draft

Manuscript Number: FUSENGDES-D-06-00066R1

Title: FINAL TEST OF THE W7-X CONTROL COILS POWER SUPPLY AND ITS INTEGRATION INTO THE OVERALL CONTROL ENVIRONMENT

Article Type: "SOFT 24th Special Issue Paper"

Section/Category: Special Issue - SOFT-24 (Proceedings of the 24th Symposium on Fusion Technology)

Keywords: WENDELSTEIN 7-X; control coils; power supply

Corresponding Author: Mr. Frank Füllenbach,

Corresponding Author's Institution: Max-Planck-Institut für Plasmaphysik

First Author: Frank Füllenbach

Order of Authors: Frank Füllenbach; Thomas Rummel; Steffen Pingel; Heike Laqua; Ina Müller; Eduardo Jauregi 


\title{
FINAL TEST OF THE W7-X CONTROL COILS POWER SUPPLY AND ITS INTEGRATION INTO THE OVERALL CONTROL ENVIRONMENT
}

\author{
$\underline{\text { F. Füllenbach }}{ }^{1}$, Th. Rummel ${ }^{1}$, S. Pingel ${ }^{1}$, H. Laqua ${ }^{1}$, I. Müller ${ }^{1}$, E. Jauregi ${ }^{2}$ \\ ${ }^{1}$ Max-Planck-Institut für Plasmaphysik, Euratom Asso ciation \\ Teilinstitut Greifswald, Wendelsteinstr. 1, D-17491 Greifswald, Germany \\ ${ }^{2}$ Grupo JEMA, Paseo del Circuito 10, E-20160 Lasarte-Oria, Guipúzcoa, Spain \\ Corresponding author. Tel.: +49-3834-882776; Fax: +49-3834-882709; \\ E-mail address: frank.fuellenbach@ipp.mpg.de
}

\begin{abstract}
In order to be able to vary the magnetic configuration of WENDELSTEIN 7-X (W7-X) at the p lasma edge and allow sweeping of the power across the divertor target plates 10 „,control coils“ are installed inside the plasma vessel behind the baffle p lates of the divertor. The coils are made of eight turns of a hollow copper profile. The dimensions of the coils are 2,05 $\mathrm{m} \times 0,35 \mathrm{~m} \times 0,35 \mathrm{~m}$ with a three dimensional shape to fit in to the narrow space between the baffles and the wall of the plas ma vessel.

Each of the ten coils is supplied by independent power supplies each providing bi-d irectionally a direct current of 2500 A with high accuracy and low ripple.

To allow sweeping the power deposition from the plasma across the target plates the power supplies provide an alternating current of up to $625 \mathrm{~A}$ with frequencies up to $20 \mathrm{~Hz}$ which is synchronis ed between the ten supplies in order to maintain the symmetry of the magnetic field.

The total output current of a power supply is a superposition of a direct current and an alternating current, where both parts have to be independ ently adjustable.

All ten power supply units and auxiliary systems have meanwhile been installed and finally tes ted at the W7-X site in Greifs wald.
\end{abstract}


The paper focuses on the results of the final tests and measures to integrate the power supply system to the overall control system including the central PLC and PC's for experiment control, data acquis itionand security systems.

Key words: WENDELSTEIN 7-X, control coils, power supply

\section{Introduction}

The main magnetic field of $\mathrm{W} 7-\mathrm{X}$ is provided by 50 non planar and 20 planar coils. To ens ure a variety of magnet field configuration at the plas ma boundary of the W7-X ma in magnetic field, to avoid symmetry breaking error fields and to sweep high peak plas ma depositions ac ross the target plates, additional normal conduc ting coils are located behind the baffle p lates of the divertor inside the plasma vessel.

The dedicated power supplies have to provide a direct current of $2500 \mathrm{~A}$ bi-directionally with high accuracy and low ripple, which can be superposed with an alternating current of $625 \mathrm{~A}$ with frequencies up to $20 \mathrm{~Hz}$ [1]. The detailed requirements are summarised in Table 1.

The complete system consists of ten independent power supplies modules (PSM), a supply distribution module (SDM) providing the mains and generating the auxiliary power, a cooling water module (CWM) for cooling the most heat excessive parts as there are the rectifier diodes, the inverter MOSFETs and the transformers. For the remote operation of the power supply a superordinated control unit (SCU) basic ally a master PLC belongs to the system as well. For low power density, hence low voltage drop and heat load in the to rus hall, $4 \times 630 \mathrm{~mm}^{2}$ cables have been chosen to connect the power supplies to the control coil.

The inverter stage of the power supply is built up by a $24 \mathrm{kHz}$ "H-bridge" converter being fed by a 12 pulse link rectifier with interphase coils. A filter composed of a capacitor and an inductance is connected to the output assuring the low voltage and current ripple requirements (Fig. 1).

\section{Results of the final tests}

After the installation and commissioning of the power supplies by the contractor Grupo Jema (Spain) each individual PSM has been tested with respect to its functionality and current performance. After these tests have been fin is hed success fully the SCU was installed and connected to the power supply. In the final test the 
overall system had to prove all main parameters given in Table 1 during combined operation from the SCU. For testing the power supplies a set of ten water cooled test coils has been purchased repres enting the electric al parameters as expected for the control coils which are namely the ohmic resis tance of 3,9 $\mathrm{m} \Omega$ and the inductance of $188 \mu \mathrm{H}$.

\subsection{Current}

For the current measurement the internal measurement devices of the PSM have been used after have been tested suffic iently during the tests of the individual PSM. The meas urement signals coming from the ten power supplies have been collected by the experimen tal data acquisition system (XDV) of IPP for further evaluation. With the data gained during the test campaign the current precis ion was measured for different current scenarios. The measured currents are well within the specified precision with values like $500 \mathrm{~A}$ to 505 A for a set point of $500 \mathrm{~A}, 1500 \mathrm{~A}$ to $1510 \mathrm{~A}$ for set a set point of $1500 \mathrm{~A}$ and $2495 \mathrm{~A}$ to $2510 \mathrm{~A}$ for a set point of $2500 \mathrm{~A}$. Several more scenario s have been tested showing the same behaviour of the current with a deviation of less then $1 \%$. Furthermore, the influence of drastic current changes in one PSM to the performance of the other PSMs due to the coupling of stray inductances of the parallel installed power lines for several PSMs was checked by changing the set point value of one PSM from 2500 A to $-2500 \mathrm{~A}$ while work ing at full DC and $\mathrm{AC}$ current. No undesired reactions in the currents were observed. As the meas urement signal coming from the in ternal current transducer of the PSM already contains a certain no is e level in a range of $0,5 \mathrm{~A}_{\mathrm{pp}}$ to $1 \mathrm{~A}_{\mathrm{pp}}$ it was decided to simulate the current ripple based upon a voltage ripple meas urement. A simulation model of the dummy coil has been developed using the simulation tool SIMPLORER $^{\mathcal{C}}$ containing the ohmic resistance, inductance and als o the parasitic capacitance of the coil, which has been calculated from the dummy coil design and afterwards verified with a meas urement at the resonance frequency of the coil. With the values from the DC voltage measurement and the coil model the current ripple was then calculated via s imulation (F ig. 2 and 3).

As expected the higher frequencies are well s moothed by the inductance of the output filter and the load itself. The Effect of the commutation frequency of $24 \mathrm{kHz}$ and its higher harmonics is negligible due to the capacitance of the output filter which is dedicated to high frequency voltage peaks coming from the inverter, whereas the sub harmonics from the $600 \mathrm{~Hz}$ inter phase coils have the main impact on the residual current 
ripple. The ripples its elf stayed inside the requirement of less than $1 \mathrm{~V}_{\mathrm{pp}}$. for the output voltage and $1 \mathrm{~A}_{\mathrm{pp}}$ for the current.

\subsection{AC Current}

First of all the AC current provided by the power supply was tested regarding the sine wave quality.

Measurement data gained with an oscilloscope were analys ed regarding the frequency and evaluated by a Fourier analyses to get the THD of the sine wave. The results show that the frequency of $20.02 \mathrm{~Hz}$ is very close to the specified value of $20 \mathrm{~Hz}$ which means a deviation of $0,1 \%$. The Fourier analys es revealed that the to talTHD is mostly composed of the third harmonic with less then $4 \%$.

As the data acquisition system which was used for the measurements of the DC current is limited to a sample frequency of $200 \mathrm{~Hz}$ it was decided to use the oscilloscope also for the measurement of the AC current precision. AC current on its own and composed with the DC current has been tested at various scenarios. The current values for the AC current were all within a current prec is ion of less than $1 \%$. Superposed to various DC current the precision of DC and AC current stayed the same as during the ind ividual tes ts of the currents. The synchronis ation of the AC current is determined by the controller of one of the PSMs. For each zero cross ing of the reference sine wave created in the controller a synchronisation interrupt is process ed in all the other modules. To evaluate quality of the synchronisation the AC current coming from this one module is taken as the reference for the measurement of the phase shift ( $\mathrm{F}$ ig. 4). The deviation of the zero cross ings of all other modules has been measured by $1,3^{\circ}$ to $1,8^{\circ}$ in different current scenarios and is therefore within the specified value.

\section{Integration into the central control environment}

As part of a complex system consis ting of numerous individual components the power supply of the control coils has its dedic ated control sys tem enabling the operator to control each individual power supply from a local operator panel (local operation) as well as from a visualization system for comb ined operation of all power supply modules and its auxiliary sys tems for maintenance and test operations (autonomous operation). In order to integrate this component and its control to the W7-X central control system [2] for the so called “segment operation" [3] during the exp erimental campaigns several interfaces have been defined (Fig. 5).

The Control system of the power supplies and the W7-X central control are bas ed upon SIEMENS S-7 hardware technology. The main interface between the power supply system and the W7-X central control is establis hed by the SCU of the power supply system and the Fast Control Station (FCS) of the W7-X central 
control. The SCU cons ists of one PLC and the dedicated communic ation hardware, being the mas ter for all control tasks of the individual PLCs of the different modules during the autonomous operation and a visualization PC as Human Machine Interface based upon SIEMENS W inCC software. Connec ted via Ethernet to the W7-X central control this PLC then works as a slave during segment operation. Internal communication between all modules of the system is also established by Profibus DP. The FCS is a local interface between its dedicated component and the central segment control being part of the W7-X central control [2]. The central segment control provides the essential data for running a segment as part of the experiment campaign and dis tributes them to the local controls tations of the different components taking part in the experiment. The FCS then sends these data to the SCU operating the system. Furthermore, the FCS collects the feedback data of the currents coming from the power supply to distribute them back to the W7-X main control and the XDV. The FCS has already been ins talled and connec ted to the power supply system while the main control ex is ts only in a preliminary status. All functionalities to test the operation of the power supply have been implemented containing the defined data packages for command, status, alarm and feedback signals as well as certain test segments provid ing the set point and limit values for the power supply. During the final test of the power supply of the control coils the functionality of the normal operation together with the existing prototypes of the W7-X main control was es tablis hed success fully. For the visualization sys tem, a stand ardized screen has been developed by IPP showing all main parameters of a component which are exchanged between the SCU and W7-X central control. This screen was implemented into the visualization system provided by the manufacturer of the power supply. As the power supply can be operated from three different places it has to be assured that no misuse of the sys tem can occur while working in a certain operation mode (local, autonomous or normal). This is managed by the so called "user rights". User rights between SCU and the local PLC of each module is determined in the SCU its elf. For changing the us er rights to the W7-X central control a stand ardized software application for the WinCC has been developed by IPP. It allows the switching of the user rights of the operator at the SCU and W7-X central control under defined conditions as well as the forcing of the us er rights back to the SCU in cas e of emergency. This software application was also scope of the test in combined operation and passed this test success fully. Apart from the software based control system an additional hardwired security bus system is foreseen to ens ure the overall personal and machine safety. First of all it has to be assumed that each component of the W7-X complies with the certain rules of personal and machine safety. Nevertheless, a residual risk ex is ts due 
to the interactions with other components while being operated combined during the normal operation of W7$\mathrm{X}$. This has a signific ant influence on the operation regime for certain components as well as for the operating staff, e.g. the access control to experiment hall. Based upon a security analyses for the power supply the potential danger coming from the power supply while working in normal operation was determined and class ified. It is planned to use the power supplies for the control coils as a test bed for a first prototype of the security bus system to test different hardware configurations for the security control. In a first step a "sys tem save" condition has been defined determined by the status of the main breakers of each PSM. An auxiliary contact of each main breaker will create this signal to be provid ed to the security bus for further ass essment. Further signals will be generated and integrated to the security bus system.

\section{Conclusions}

The ten power supplies for the control coils has been finally ins talled, commiss ioned and completely tested. The control sys tem has been tested too. It is compatible to the preliminary main control sys tem of W7-X which is currently under design. Ongoing activities will be the adjustment of the control system to further modification and completion of the W7-X main control and the establishing of the security bus system. As the first control coil will arrive soon in Gre ifswald the power supply will be prepared to supply this coils for further in ternal tests.

\section{References}

[1] Thomas Rummel, F. Füllenbach, Th. Mönnich: Power supplies for the WENDELSTEIN 7-X stellerator, Fusion Engineering and Design 66-68 (2003), available online at www.sciencedirect.com

[2] J. Schacht, H. Niedermeyer, H. Laqua, A. Spring, I. Müller, St. Pingel and A. Wölk: Tasks and structure of the WENDELSTEIN7-X control system, Fusion Engineering and Design, to be published, Corrected Proof available online at www.sciencedirect.com 22 May 2006.

[3] H. Laqua, H. Nied ermeyer, J. Schacht, A. Spring: Real-time Software for the Fusion Experiment WENDELSTEIN 7-X, Fusion Engineering and Design, to be published, Corrected Proof availab le online at www.sciencedirect.com 5 June 2006. 


\begin{tabular}{|l|l|l|}
\hline Designation & Value & Unit \\
\hline DC current & 0 to \pm 2500 & $\mathrm{~A}$ \\
\hline AC Current & 625 & $\mathrm{~A}_{\mathrm{p}}$ \\
\hline Maximum peak current & 3125 & $\mathrm{~A}$ \\
\hline Frequency of the AC current & $0-20$ & $\mathrm{~Hz}$ \\
\hline Ripple of the DC current & $\leq 1$ & $\mathrm{~A}_{\mathrm{pp}}$ \\
\hline Deviation from setpoint value & $\leq 16$ & $\mathrm{~A}$ \\
\hline THD of the AC current & $\leq 10$ & $\%$ \\
\hline Phase shift between AC currents & $\leq 2$ & $\circ$ \\
\hline Effec tive voltage & 30 & $\mathrm{~V}$ \\
\hline Ripple of the DC voltage & 1 & $\mathrm{~V}_{\mathrm{pp}}$ \\
\hline Power losses & 10 & $\mathrm{~kW}$ \\
\hline
\end{tabular}


Fig. 1 Scheme of the power supply for the control coils
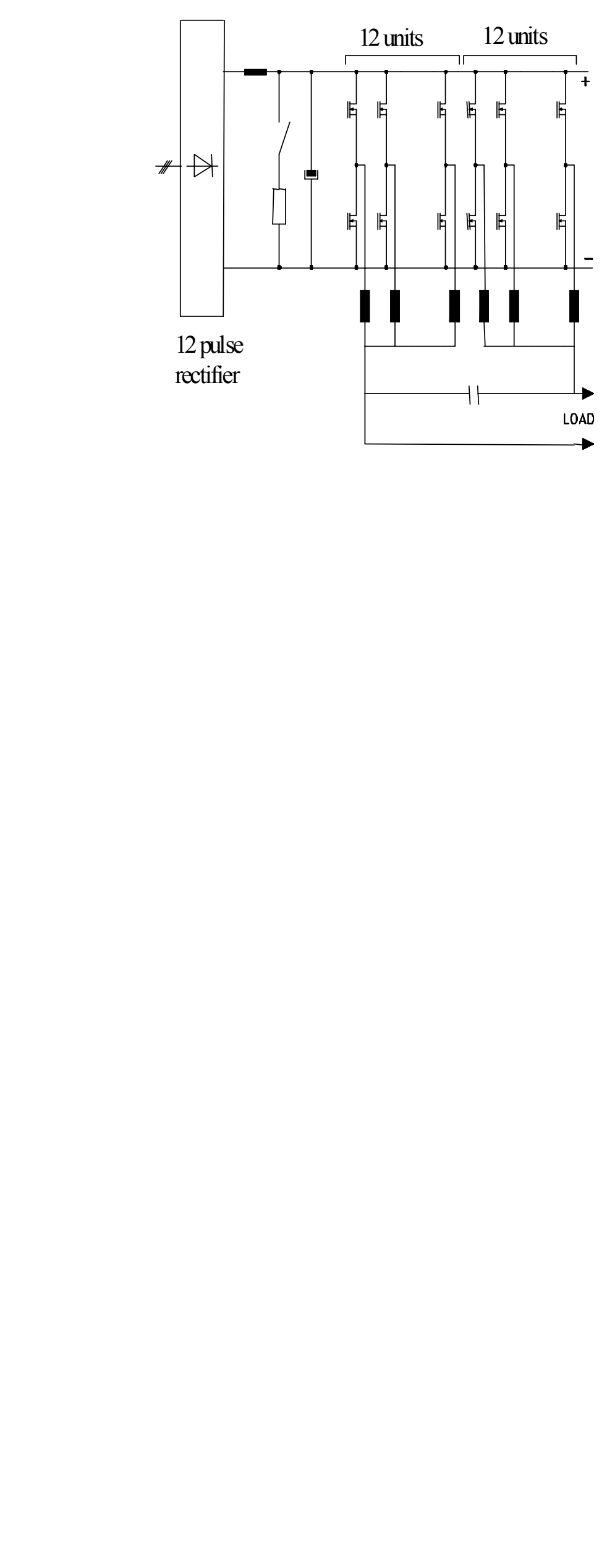


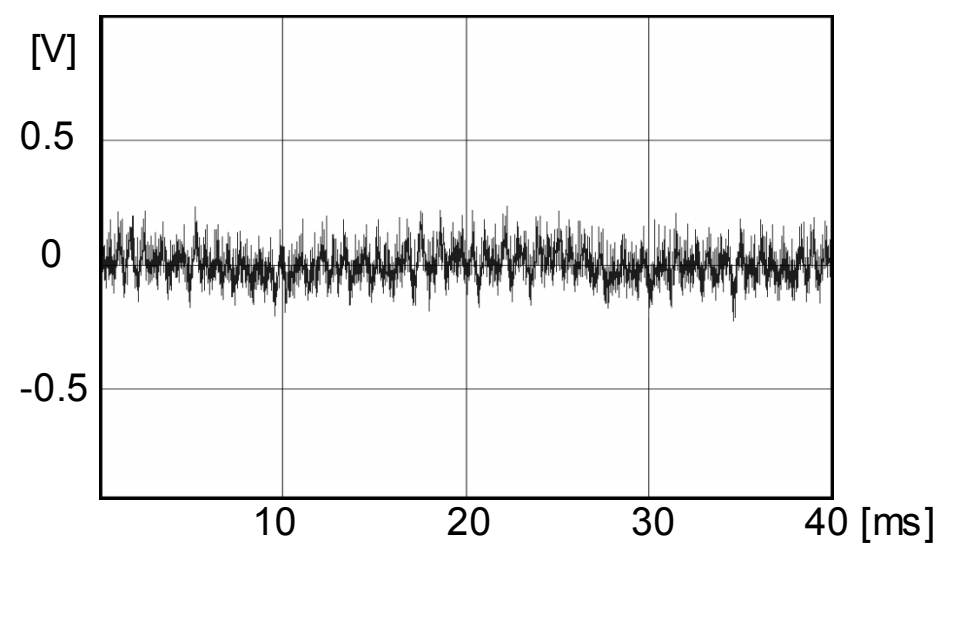

Fig. 2 Measured voltage ripple at 2500 A
\begin{tabular}{ll|l|l|l|}
\hline \\
$\qquad .5$ & & & \\
\hline & 0 \\
-0.5 & & & \\
\hline
\end{tabular}
\[ \]
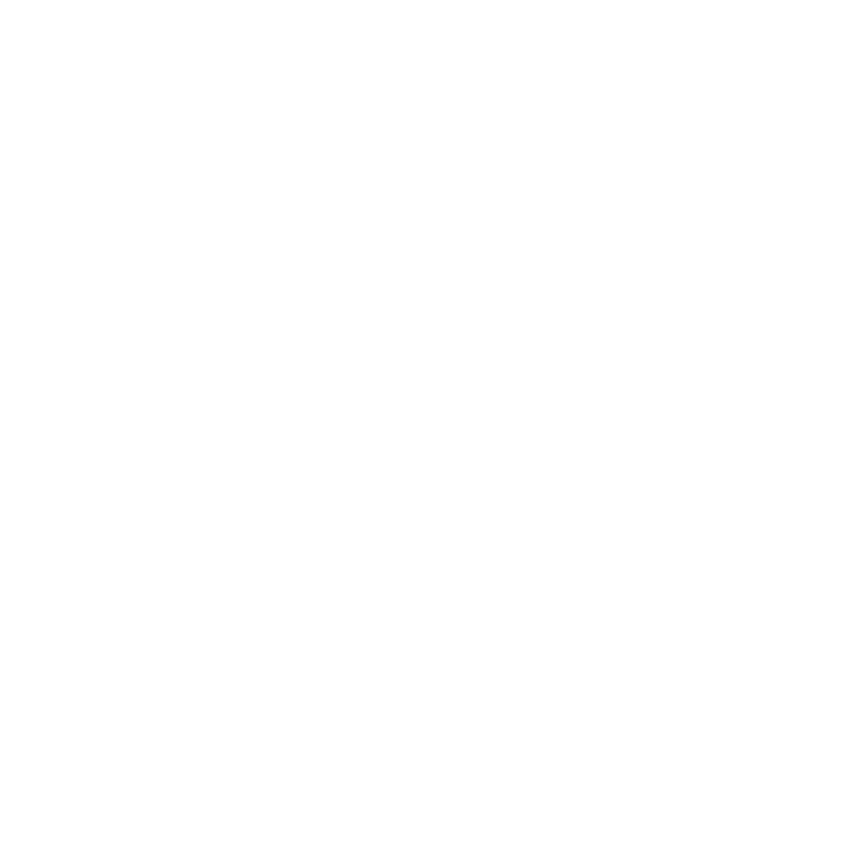

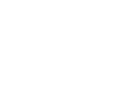

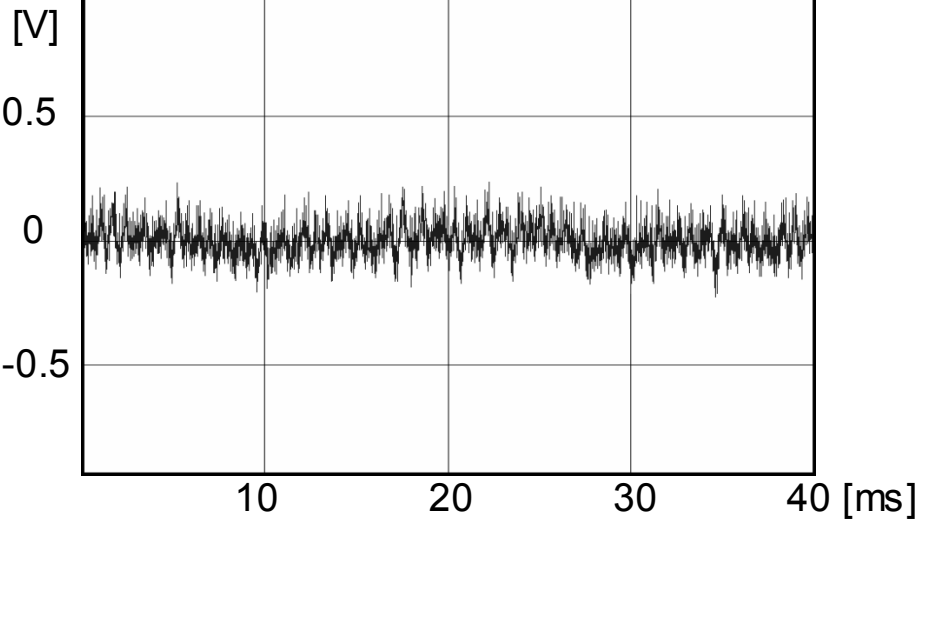




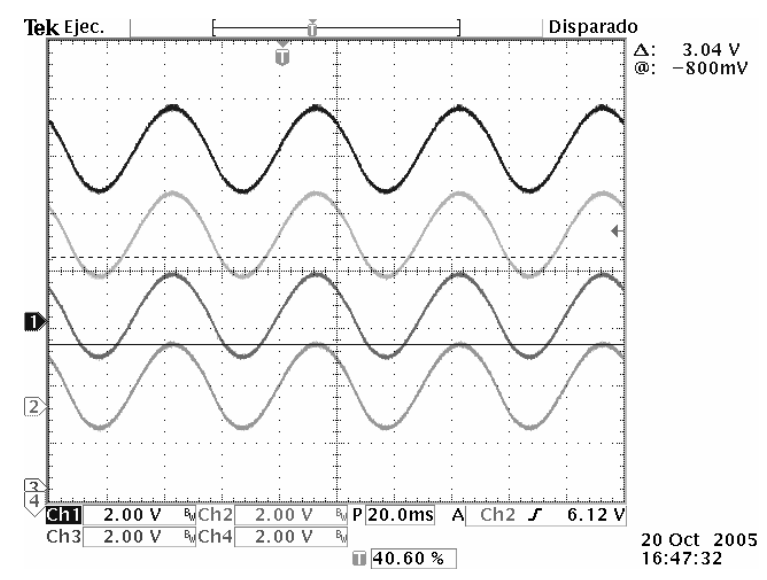

Fig. 4 Ref. AC current (top) and three adjacent modules 


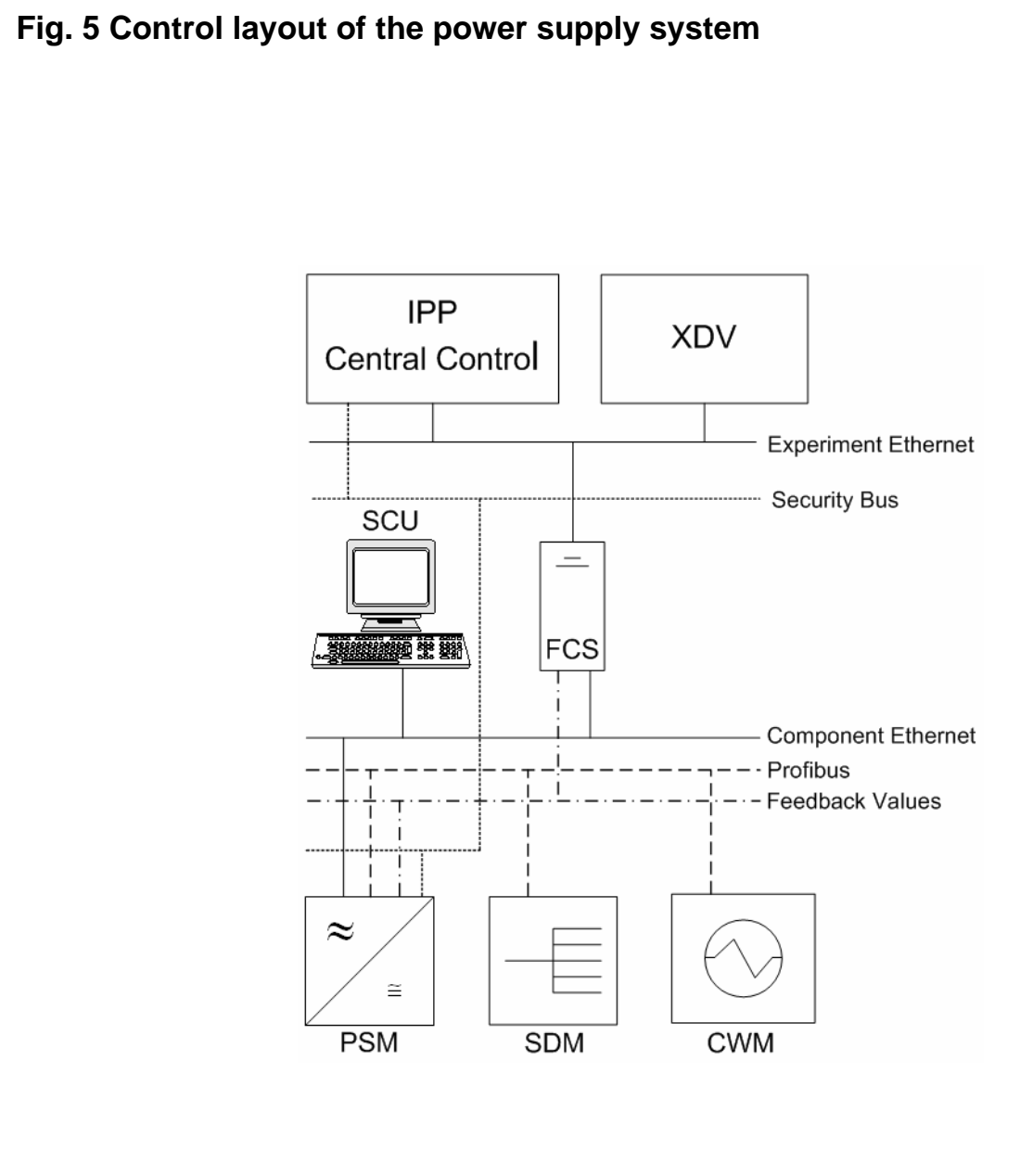

Fig. 5 Control layout of the power supply system

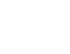
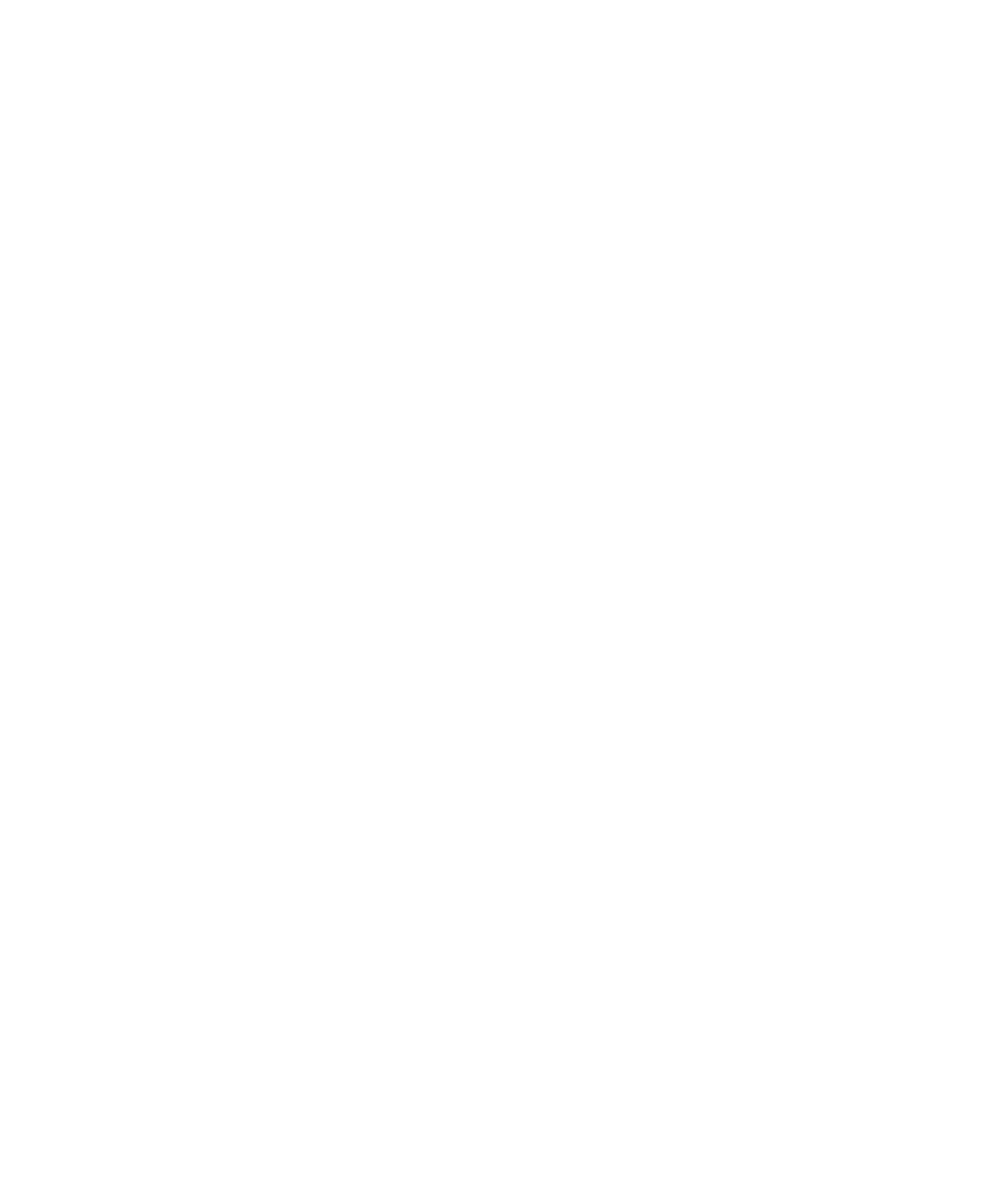

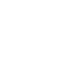
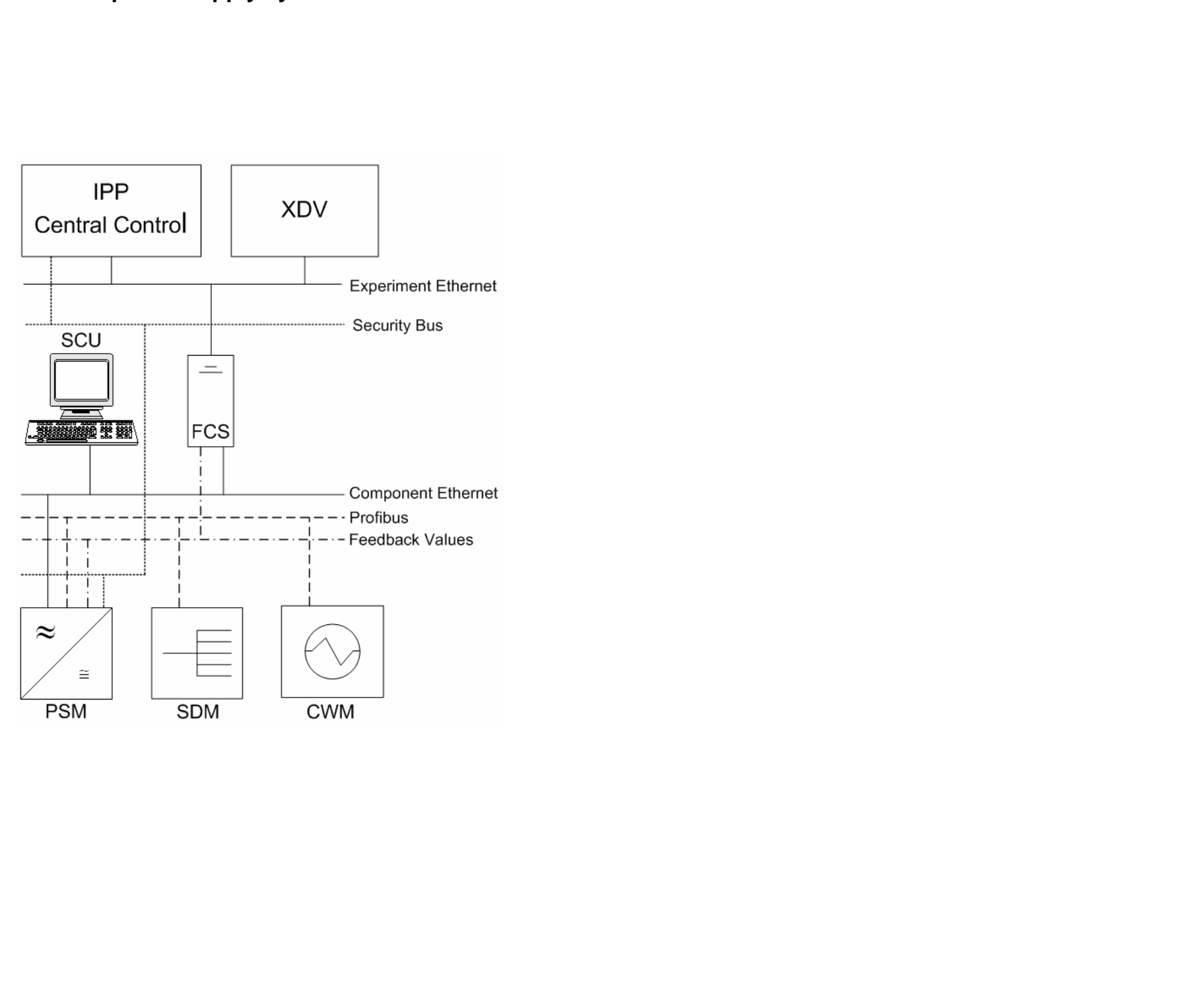
Detailed Response to Reviewers
This piece of the submission is being sent via mail.

Detailed Response to Reviewers
This piece of the submission is being sent via mail.

This piece of the submission is being sent via mail.

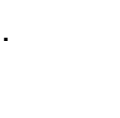

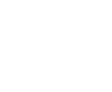

This piece the submission is being sent via mail.

This piece the submission is being sent via mail.

This piece the submission is being sent via mail.

2

$\left(\frac{10}{2}\right.$

(1)

(1)

(2)

$\sqrt{2}$

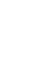

(1)

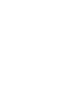

(1)

(1)

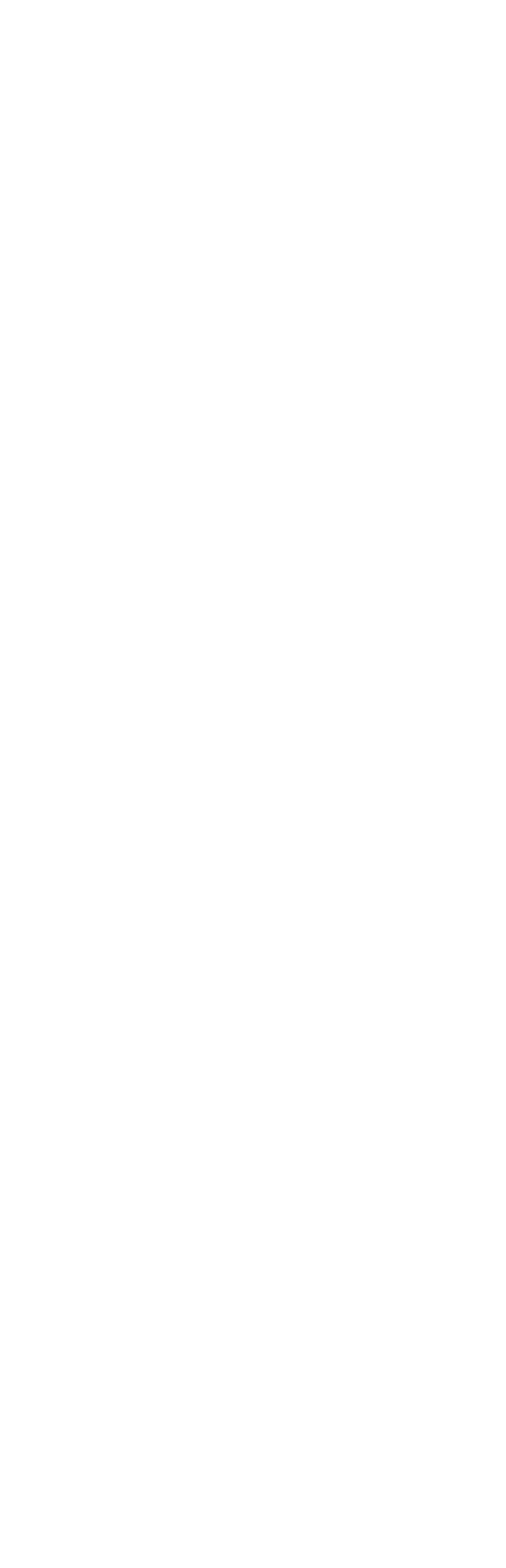

